\title{
POLÍTICAS PÚBLICAS E PROTEÇÃO AMBIENTAL: ANÁLISE DAS MEDIDAS LEGAIS APLICÁVEIS A UMA BACIA HIDROGRÁFICA PAULISTA
}

\author{
Fernando Henrique Machado ${ }^{1}$ \\ Universidade Estadual Paulista Júlio de Mesquita Filho (UNESP) \\ Instituto de Ciência e Tecnologia (ICTS) \\ Programa de Pós-graduação em Ciências Ambientais (PGCA) \\ Felipe Hashimoto Fengler $^{2}$ \\ Universidade Estadual Paulista Júlio de Mesquita Filho (UNESP) \\ Instituto de Ciência e Tecnologia (ICTS) \\ Programa de Pós-graduação em Ciências Ambientais (PGCA)
}

Gerson Araujo de Medeiros ${ }^{3}$

Universidade Estadual Paulista Júlio de Mesquita Filho (UNESP)

Instituto de Ciência e Tecnologia (ICTS)

Programa de Pós-graduação em Ciências Ambientais (PGCA)

\section{RESUMO}

A bacia hidrográfica do rio Jundiaí-Mirim (BH-JM) é o principal manancial de abastecimento público de Jundiaí-SP. Nas últimas décadas o acentuado crescimento econômico e populacional ocasionou inúmeras externalidades, sobretudo àquelas relacionadas à degradação ambiental. À vista disso, políticas públicas ambientais, materializadas por meio de atos normativos, representam importantes instrumentos de análise a fim de avaliar a efetividade da tutela ambiental pelo Estado. Nessa perspectiva, este estudo visou identificar e discutir as políticas públicas ambientais de natureza legal relacionadas à BH-JM. Para este fim, utilizou-se de pesquisa

\footnotetext{
1 Doutor em Ciências Ambientais pelo Instituto de Ciência e Tecnologia da Universidade Estadual Paulista Júlio de Mesquita Filho (ICTS/UNESP). Mestre em Meio Ambiente e Recursos Hídricos pela Universidade Federal de Itajubá (UNIFEI). Especialista em Tecnologia Ambiental pelo Departamento de Engenharia Ambiental e Sanitária da Universidade Federal de Minas Gerais (DESA/UFMG). Bacharel em Administração/Gestão Ambiental pela Escola Superior em Meio Ambiente (ESMA). ORCID: https://orcid.org/0000-0002-9717-4765 / e-mail: fernandomtb@hotmail.com

2 Doutor em Ciências Ambientais pelo Instituto de Ciência e Tecnologia da Universidade Estadual Paulista Júlio de Mesquita Filho (ICTS/UNESP). Mestre em Agricultura Tropical e Subtropical pelo Instituto Agronômico (IAC). Bacharel em Engenharia Ambiental pelo ICTS/UNESP. ORCID: https:// orcid.org/0000-0002-7982-2300 / e-mail: felipe_fengler@hotmail.com

3 Pós-Doutor pela University of Alberta (UALBERTA). Doutor e Mestre em Engenharia Agrícola pela Universidade Estadual de Campinas (UNICAMP). Professor da Universidade Estadual Paulista Júlio de Mesquita Filho (UNESP). ORCID: https://orcid.org/0000-0002-9122-3909 / e-mail: gerson@ sorocaba.unesp.br
} 
bibliográfica e documental, em que foi empregada uma abordagem histórico-descritiva na análise do aparato legislativo ambiental estadual e municipal. Identificaram-se 14 medidas legais em vigor aplicáveis à $\mathrm{BH}$ -JM, sendo: 9 normas municipais (8 Leis e 1 Resolução); e 5 estaduais (1 Lei; 3 Decretos; e 1 Resolução). A análise realizada constatou que Jundiaí apresenta um arcabouço jurídico abrangente; contudo, notou-se uma baixa efetividade jurídica na sua implementação quando os requisitos estabelecidos são confrontados com os diagnósticos ambientais existentes. Destarte, observou-se a necessidade de uma maior intervenção do Estado e participação da coletividade visando o efetivo cumprimento das normas estabelecidas. Ademais, diretrizes de gestão a fim de subsidiar um melhor manejo da bacia foram propostas.

Palavras-chave: Legislação Ambiental; Pressão Antrópica; Bacias PCJ; Jundiaí-Mirim.

\section{PUBLIC POLICIES AND ENVIRONMENTAL PROTECTION: ANALYSIS OF ENVIRONMENTAL LEGISLATION APPLICABLE TO A RIVER BASIN IN SOUTHEAST BRAZIL}

\section{ABSTRACT}

The Jundiai-Mirim River Basin (BH-JM) is the most important source of public water supply in Jundiai (SP). In the last decades, the accentuated economic and population growth has caused countless externalities, such as environmental degradation. For thisreason, studies related to environmental public policies represent important analytical instruments for management purposes in order to evaluate the effectiveness of environmental protection by the State. Thus, this study aimed to identify and discuss public environmental policies (of legal nature) related to the Jundiai-Mirim River Basin (BH-JM). For this purpose, a bibliographical and documentary research was used, along with a historical-descriptive approach in order to analyze the state and municipal environmental legislation. We identified 14 public regulatory applicable to BH-JM: 9 municipals (8 Laws and 1 Resolution); and 5 state (1 Law, 3 Decrees, and 1 Resolution). The analysis showed that Jundiai has a broad legal framework; nevertheless, there was limited legal effectiveness in its implementation when the established requirements are compared with existing environmental studies. For 
this reason, the need for more government intervention and community participation was observed, in order to ensure effective compliance with the established laws. Furthermore, management guidelines were proposed in to subsidize better management of the river basin.

Keywords: Antropogenic Pressure; Environmental legislation; Jundiai-Mirim; PCJ River Basins.

\section{INTRODUÇÃO}

O município de Jundiaí (SP) evidenciou um acentuado crescimento econômico e populacional nas últimas décadas. Dentre os indicadores desse crescimento, destaca-se o PIB per capta municipal de R $\$ 94$ mil ano $^{-1}$ (SEADE, 2014) e a taxa média de crescimento anual (1,07\% a.a.) (SEADE, 2016) - cujos resultados se revelam superiores ao do Estado (i.e., R \$ 44 mil ano $^{-1}$ e $0,85 \%$ a.a., respectivamente). No Brasil, o crescimento econômico e populacional sem o devido planejamento denota inúmeras externalidades, principalmente àquelas relacionadas à degradação ambiental, exigindo, portanto, ações concretas da administração pública no que tange a proteção ambiental (MELLO; SATHLER, 2015; MEDEIROS et al., 2017). Nessa perspectiva, os estudos relacionados a políticas públicas ambientais representam instrumentos importantes de análise, uma vez que estes fornecem uma regulamentação governamental necessária à melhoria da qualidade ambiental (REVESZ; STAVINS, 2007; SPADOTTO; BARREIRO; MEDEIROS, 2017).

De acordo com Souza (2006), o estudo de políticas públicas emerge da necessidade de entender as razões e circunstâncias as quais os governos determinam e direcionam suas ações. Na formulação das políticas públicas os governantes traduzem e executam seus propósitos por meio de planos, programas e projetos (i.e., colocam o governo em ação), resultando, assim, em eventuais benefícios aos governados. Souza (2006) sumarizou, ainda, os principais elementos que constituem as políticas públicas, dentre os quais: o que o governo intenta fazer e o que, de fato, faz; envolve múltiplos atores formais e informais; não se limita a criação de leis e regras; baseia-se em objetivos e, essencialmente, é de longo prazo - apesar de resultar benefícios de curto prazo.

Dessa forma, verifica-se a abrangência teórico-conceitual das políticas públicas, bem como a infinidade de elementos que podem compô-las. 
Neste estudo, pautou-se em discutir as políticas públicas materializadas por meio de atos normativos - embora, conforme destacado preliminarmente, tais não se limitam somente a esse aspecto. À vista disso, o problema de pesquisa emergiu da necessidade de uma maior reflexão sobre as lacunas, limitações e horizontes das políticas públicas ambientais voltadas à proteção ambiental de bacias hidrográficas. Nestas, dada sua abrangência territorial poder envolver mais de um município, mesmo com a existência de requisitos legais, uma tutela jurisdicional eficiente dessas áreas se esbarram nos interesses difusos dos diversos atores sociais envolvidos.

Nesse contexto, este estudo visou identificar e discutir as políticas públicas de natureza legal de proteção ambiental aplicáveis à bacia hidrográfica do rio Jundiaí-Mirim (BH-JM), bem como analisar a efetividade de aplicação destas pelo Estado na tutela deste bem ambiental. Para este fim, foram levantados atos normativos na base legislativa estadual (São Paulo) e municipal (Jundiaí). Assim, primeiramente é apresentado a área objeto de estudo, bem como o método de pesquisa adotado e respectivos critérios de pesquisa; posteriormente são apresentados os resultados e discussões relativas aos atos normativos identificados; e, por fim, são apresentadas as principais conclusões diante dos resultados encontrados.

\section{OBJETO DE ESTUDO}

A BH-JM (Figura 1) representa a principal fonte de abastecimento público de Jundiaí, sendo responsável pelo fornecimento de $95 \%$ da água fornecida ao município (COBRAPE, 2016), cuja população é estimada em 414.810 habitantes (IBGE, 2018). A BH-JM tem $118 \mathrm{~km}^{2}$ de área de drenagem, e seus limites abrangem Jundiaí (SP) (55\%), Jarinu (SP) (36,6\%) e Campo Limpo Paulista (SP) (8,4\%) (FENGLER et al., 2015b). A BH-JM tem experimentado nas últimas décadas um intenso processo de urbanização, valorização do preço das terras, além de atividades agrícolas e mineração (FREITAS et al., 2013; FENGLER et al., 2015b). Como reflexo desse uso e ocupação do solo, tem sido observado uma superexploração dos recursos hídricos acima da sua capacidade natural (MACHADO et al., 2018); degradação na qualidade da água de seus afluentes e reservatórios (BEGHELLI et al., 2015; DE-CARLI et al., 2018; MACHADO et al., 2018); supressão dos fragmentos florestais (FENGLER et al., 2015b); transporte de sedimentos e erosão (FENGLER et al., 2015a; MEDEIROS et al., 2016; SILVA; MEDEIROS, 2017). 


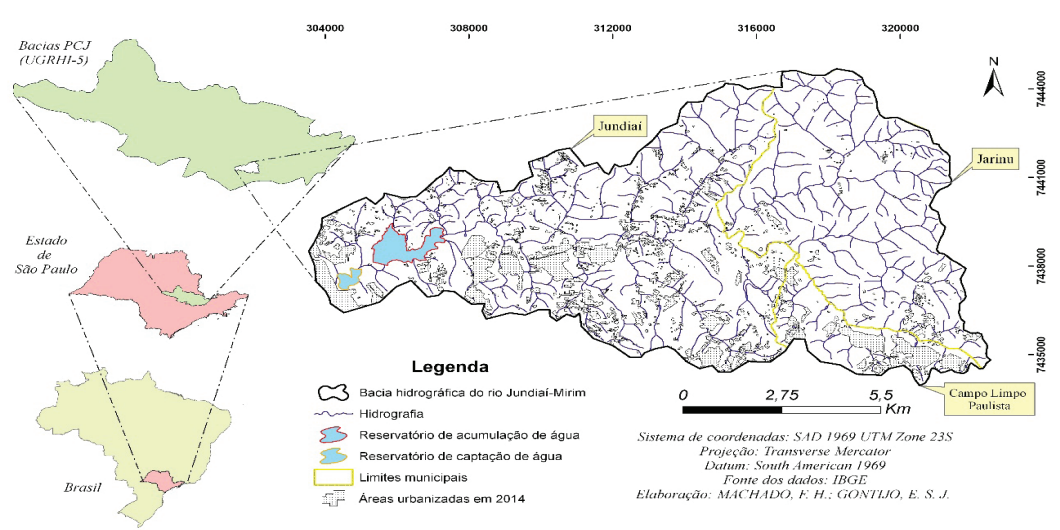

Figura 1 Localização da bacia hidrográfica do rio Jundiaí-Mirim (BH-JM).

Fonte: autoria própria.

\section{MÉTODO DE PESQUISA}

O desenvolvimento metodológico se deu por meio de pesquisa bibliográfica e documental, em que foi utilizada uma abordagem histórico-descritiva do aparato legislativo ambiental aplicável à BH-JM. Esta abordagem fundamenta-se na descrição do objeto em análise e o consequente estabelecimento de relações com outros atributos (GIL, 2008). A pesquisa documental foi realizada por meio da consulta de atos normativos (em vigor) relativos a medidas protecionistas da BH-JM; já a pesquisa bibliográfica visou identificar bibliografias a fim de subsidiar as discussões.

Destaca-se que parte da bibliografia consultada se constituiu de diagnósticos ambientais da BH-JM que vem sendo conduzidos há cerca de duas décadas por uma equipe multidisciplinar vinculada ao Instituto Agronômico (IAC) e ao Instituto de Ciência e Tecnologia de Sorocaba, da Universidade Estadual Paulista (ICTS-UNESP).

No âmbito legislativo foram consultadas as bases de dispositivos legais apresentadas no Quadro 1, sem restrição temporal, cujas palavras-chave utilizadas na pesquisa foram: Jundiaí-Mirim; Jundiaí Mirim; Jundiaí Mirim; e bacia hidrográfica do rio Jundiaí-Mirim. Durante a consulta, pelo fato de o município ter um bairro homônimo, foram excluídos todos os resultados que retomassem a essa informação. 
Quadro 1 Base de dados consultados no levantamento do aparato legislativo-ambiental da BH-JM

\begin{tabular}{|c|c|c|c|}
\hline Base & Sub-base & Filtros utilizados & Fonte \\
\hline $\begin{array}{l}\text { Assembleia Legislativa } \\
\text { do Estado de São Paulo } \\
\text { (ALESP) }\end{array}$ & $\begin{array}{l}\text { Base de Legislação } \\
\text { do Estado de São } \\
\text { Paulo }\end{array}$ & $\begin{array}{l}\text { - Leis Ordinárias } \\
\text { - Leis Complementares } \\
\text { - Emenda Constitu- } \\
\text { cional } \\
\text { - Resoluções da } \\
\text { ALESP } \\
\text { - Resoluções } \\
\text { - Decretos do Exe- } \\
\text { cutivo } \\
\text { - Decretos Legislativos } \\
\text { - Decretos-Leis } \\
\text { - Decretos-Leis Com- } \\
\text { plementares } \\
\text { - Atos e Decisões da } \\
\text { ALESP }\end{array}$ & $\operatorname{ALESP}([$ s.d.] $)$ \\
\hline \multirow[t]{2}{*}{$\begin{array}{l}\text { Prefeitura Municipal de } \\
\text { Jundiaí (PMJ) }\end{array}$} & $\begin{array}{l}\text { Unidade de Gestão } \\
\text { de Planejamento } \\
\text { Urbano e Meio } \\
\text { Ambiente }\end{array}$ & $\begin{array}{l}\text { - Leis Ambientais } \\
\text { - Atos Normativos }\end{array}$ & PMJ (2016?-a) \\
\hline & $\begin{array}{l}\text { Departamento de } \\
\text { Licenciamento de } \\
\text { Obras e Instalações } \\
\text { (DELOI) }\end{array}$ & - Legislação & PMJ (2016?-b) \\
\hline $\begin{array}{l}\text { Câmara Municipal de } \\
\text { Jundiaí (CMJ) }\end{array}$ & $\begin{array}{l}\text { OpenLegis - Sistema } \\
\text { Aberto de Gestão } \\
\text { Legislativa }\end{array}$ & $\begin{array}{l}\text { - Normas Jurídicas } \\
\text { - Ato Legislativo } \\
\text { - } \text { Decreto do Execu- } \\
\text { tivo } \\
\text { - Decreto Legislativo } \\
\text { - Emenda à Lei Or- } \\
\text { gânica } \\
\text { - Lei } \\
\text { - Lei complementar } \\
\text { - Portaria } \\
\text { - Resolução }\end{array}$ & CMJ ([s.d.]) \\
\hline $\begin{array}{l}\text { Departamento de Água e } \\
\text { Esgoto de Jundiaí (DAE } \\
\text { Jundiaí) }\end{array}$ & Legislação & $\begin{array}{l}\text { - Legislação Muni- } \\
\text { cipal } \\
\text { - Legislação Estadual } \\
\text { - Portarias DAE } \\
\text { - Normas Técnicas }\end{array}$ & $\operatorname{DAE}(2017 a)$ \\
\hline
\end{tabular}

Fonte: autoria própria.

\section{RESULTADOS}

A partir dos critérios estabelecidos, foi possível identificar 14 medidas legais em vigor aplicáveis direta ou indiretamente à BH-JM, sendo 9 normas municipais (das quais: 8 Leis e 1 Resolução) e 5 estaduais (das quais: 1 Lei; 3 Decretos; e 1 Resolução). No Quadro 2 são apresentadas as políticas públicas (medidas legais) identificadas relacionadas à proteção da BH-JM, assim como seus respectivos propósitos: 
Quadro 2 Medidas legais de proteção ambiental relacionadas à BH-JM

\begin{tabular}{|c|c|c|}
\hline $\begin{array}{l}\text { Políticas públicas } \\
\text { (medidas legais) }\end{array}$ & Principais propósitos & Fonte \\
\hline $\begin{array}{l}\text { Lei Municipal n. } 2.405 \text {, de } \\
10 \text { de Junho de } 1980 \\
\text { (Lei de proteção aos } \\
\text { mananciais - atualizada } \\
\text { até a Lei } 7.503 \text { de } 2010 \text { ) }\end{array}$ & $\begin{array}{l}\text { - Disciplinou o uso do solo visando } \\
\text { à proteção das coleções hídricas de } \\
\text { Jundiaí } \\
\text { - Estabeleceu como área de proteção } \\
\text { ambiental a BH-JM da barragem de } \\
\text { captação até os limites municipais, } \\
\text { incluindo todos os afluentes do rio } \\
\text { Jundiaí-Mirim } \\
\text { - Estabeleceu que projetos de urbaniza- } \\
\text { ção ou qualquer atividade econômica } \\
\text { na BH-JM devem ter anuência dos } \\
\text { órgãos competentes municipais, } \\
\text { inclusive do DAE S.A. Jundiaí; } \\
\text { - Uso prioritário das águas da BHJM } \\
\text { para o abastecimento público } \\
\text { - Proibiu a pesca, esportes náuticos ou } \\
\text { outras atividades que possam preju- } \\
\text { dicar a qualidade da água dos reser- } \\
\text { vatórios de abastecimento públicos } \\
\text { localizados na BH-JM; } \\
\text { - Proibiu empreendimentos que tenham } \\
\text { efluente líquido que possam afetar a } \\
\text { qualidade das águas protegidas pela } \\
\text { Lei } \\
\text { mestringiu à expansão de empreendi- } \\
\text { proteção dos mananciais }\end{array}$ & Jundiaí (1980) \\
\hline $\begin{array}{l}\text { Lei Estadual n. } 4.095 \text {, de } \\
12 \text { de junho de } 1984 \\
\text { (atualizada até a Lei n. } \\
\text { 12.290, de } 02 \text { de março } \\
\text { de } 2006 \text { ) }\end{array}$ & $\begin{array}{l}\text { Declarou a Área de Proteção Am- } \\
\text { biental (APA) a região urbana e rural } \\
\text { de Jundiaí, incluindo toda a área de } \\
\text { drenagem da BH-JM; } \\
\text { - Restringiu atividades e obras de } \\
\text { terraplanagem que podem provocar a } \\
\text { acelerada perda de solo. }\end{array}$ & São Paulo (1984) \\
\hline $\begin{array}{l}\text { Decreto Estadual n. } \\
24.839 \text {, de } 06 \text { de março } \\
\text { de } 1986\end{array}$ & $\begin{array}{l}\text { - Enquadrou o rio Jundiaí-Mirim e seus } \\
\text { afluentes em cursos d'água Classe } 1 .\end{array}$ & São Paulo (1986) \\
\hline $\begin{array}{l}\text { Lei orgânica do município } \\
\text { de Jundiaí, de } 05 \text { de abril } \\
\text { de } 1990 \text { (atualizada até } 22 \\
\text { de dezembro de 2015) }\end{array}$ & $\begin{array}{l}\text { - Estabeleceu a BH-JM como área de } \\
\text { proteção ambiental; } \\
\text { - Proibiu o lançamento de resíduos } \\
\text { industriais e orgânicos na BH-JM. }\end{array}$ & Jundiaí (2015b) \\
\hline $\begin{array}{l}\text { Lei Municipal n. } 3.522 \text {, de } \\
06 \text { de abril de } 1990\end{array}$ & $\begin{array}{l}\text { - Proibiu o lançamento de qualquer } \\
\text { substância poluidora oriunda de } \\
\text { atividades econômicas nas águas da } \\
\text { BH-JM; } \\
\text { - Estabelece sanções pecuniárias aos } \\
\text { infratores. }\end{array}$ & Jundiaí (1990) \\
\hline
\end{tabular}




\begin{tabular}{|c|c|c|}
\hline $\begin{array}{l}\text { Lei Municipal n. } 5.032 \text {, de } \\
08 \text { de setembro de } 1997\end{array}$ & $\begin{array}{l}\text { Autorizou o DAE Jundiaí a fornecer } \\
\text { água não tratada do rio Jundiaí-Mirim } \\
\text { a empresas que utilizam este recurso } \\
\text { em seus processos produtivos. }\end{array}$ & Jundiaí (1997) \\
\hline $\begin{array}{l}\text { Decreto Estadual n. } \\
\text { 43.284, de } 03 \text { de julho de } \\
1998\end{array}$ & $\begin{array}{l}\text { - Estabeleceu a Zona de Conservação } \\
\text { Hídrica a fim de proteger em termos } \\
\text { qualitativos e quantitativos os cursos } \\
\text { d'água mananciais da APA Jundiaí e, } \\
\text { especificamente, a BH-JM. }\end{array}$ & São Paulo (1998) \\
\hline $\begin{array}{l}\text { Lei Municipal n. } 5.221 \text {, de } \\
31 \text { de dezembro de } 1998\end{array}$ & $\begin{array}{l}\text { - Autorizou o DAE alienar áreas pú- } \\
\text { blicas para implantação de equipa- } \\
\text { mentos recreativos e urbanização no } \\
\text { entorno da represa de acumulação de } \\
\text { Jundiaí. }\end{array}$ & Jundiaí (1998b) \\
\hline $\begin{array}{l}\text { Decreto Municipal n. } \\
18.148 / 2001\end{array}$ & $\begin{array}{l}\text { Destacou a necessidade, a nível muni- } \\
\text { cipal, da rigorosa observância as nor- } \\
\text { mas estaduais e federais na delimita- } \\
\text { ção de áreas de preservação ambiental } \\
\text { situadas ao longo dos cursos d'água, } \\
\text { lagoas, nascentes e reservatórios. }\end{array}$ & Jundiaí (2001) \\
\hline $\begin{array}{l}\text { Lei Municipal n. } 8.203 \text {, de } \\
28 \text { de abril de } 2014\end{array}$ & $\begin{array}{l}\text { Incluiu investimentos financeiros para } \\
\text { obras de complementação da barra- } \\
\text { gem do rio Jundiaí-Mirim no Plano } \\
\text { Plurianual Municipal. }\end{array}$ & Jundiaí (2014a) \\
\hline $\begin{array}{l}\text { Resolução Estadual } \\
\text { Conjunta SMA/SSRH n. } \\
001 \text {, de } 05 \text { de junho de } \\
2014\end{array}$ & $\begin{array}{l}\text { Destinou a BH-JM (e outras bacias) } \\
\text { recursos financeiros a fim da recu- } \\
\text { peração de suas matas ciliares e à } \\
\text { recomposição da vegetação. }\end{array}$ & São Paulo (2014b) \\
\hline $\begin{array}{l}\text { Lei Municipal n. } 8.607 \text {, de } \\
16 \text { de março de } 2016\end{array}$ & $\begin{array}{l}\text { Criou o programa "Nascentes de Jun- } \\
\text { diaí" visando à conservação, recupe- } \\
\text { ração e proteção dos mananciais; } \\
\text { - Autorizou o poder executivo prestar } \\
\text { apoio financeiro e/ou técnico aos } \\
\text { proprietários rurais que aderirem ao } \\
\text { programa. }\end{array}$ & Jundiaí (2016a) \\
\hline $\begin{array}{l}\text { Lei Municipal n. } 8.673 \text {, de } \\
15 \text { de junho de } 2016\end{array}$ & $\begin{array}{l}\text { - Instituiu, nas datas comemorativas } \\
\text { ambientais do município, o dia do rio } \\
\text { Jundiaí-Mirim. }\end{array}$ & Jundiaí (2016b) \\
\hline $\begin{array}{l}\text { Lei Municipal n. } 8.683 \text {, de } \\
07 \text { de julho de } 2016\end{array}$ & $\begin{array}{l}\text { - Institui o Plano Diretor do Município } \\
\text { de Jundiaí; } \\
\text { - Criou a Zona de Proteção e Recupe- } \\
\text { ração Ambiental das Bacias dos Rios } \\
\text { Jundiaí- Mirim e Capivari e Ribeirão } \\
\text { Cachoeira/Caxambu. }\end{array}$ & Jundiaí (2016c) \\
\hline
\end{tabular}

Fonte: resultados da pesquisa. 


\section{DISCUSSÕES}

\subsection{Leis gerais municipais relacionadas à proteção do meio ambiente e recursos hídricos}

$\mathrm{Na}$ análise da Lei Orgânica do Município de Jundiaí (JUNDIAÍ, 2015b), foi possível constatar medidas legais protecionistas relacionadas diretamente à $\mathrm{BH}-\mathrm{JM}$ e demais cursos d'água mananciais da cidade, como o córrego do Moisés e ribeirão Caxambu (declarados como áreas de proteção ambiental). Do mesmo modo, no capítulo IV (do Meio Ambiente) desta Lei é destacado que as nascentes localizadas no território do município devem ser protegidas pelo Poder Público, assim como as suas paisagens notáveis; observa-se, assim, a contemporaneidade na inserção de requisitos protecionistas na Lei maior do município. Entretanto, embora tal previsão fosse prevista desde o Código Florestal de 1965, a proteção dessas áreas revelou-se ineficaz - sobretudo no tange as nascentes, uma vez que o levantamento feito pelo poder público local indicou que, das 1,4 mil nascentes do município, 390 (28\%) estavam degradadas e 456 (33\%) mereciam estado de atenção (OLIVEIRA, 2016).

Por sua vez, o Decreto Municipal n. 18.148/2001 (Jundiaí, 2001) aborda sobre o compromisso do munícipio com as normas estaduais e federais relativas à criação de faixas de proteção ambiental, situadas às margens dos cursos d'água, lagos, nascentes e reservatórios. Logo, não traz nenhuma nova regulamentação, porém reforça o compromisso do município em atender rigorosamente às disposições estabelecidas por estas normas externas ao município. Este Decreto reforçou, ainda, a necessidade de licenciamento ambiental quando os dispositivos legais estaduais e federais não puderem ser atendidos nas referidas áreas.

Com base nos estudos de Freitas et al. (2013) é possível auferir uma baixa efetividade jurídica a esse Decreto, uma vez que os autores constataram que $55 \%$ das áreas de preservação permanente (APPs) da BH-JM estavam em desacordo com o preconizado na legislação federal à época. Fengler et al. (2015b) verificaram, ainda, que no período de 1972 a 2013 a área urbanizada se expandiu em 592\%, fato do qual coloca a pressão antrópica como a principal indutora de perturbação dessas áreas. Todavia, observou-se um declínio nessa taxa de crescimento quando comparados os períodos de 1972 a $2001\left(48,1\right.$ ha ano $\left.^{-1}\right)$ e 2001 a $2013\left(29,7\right.$ ha ano $\left.{ }^{-1}\right)$. Tal evento contribuiu para reduzir a taxa de crescimento dessa perturbação nos fragmentos florestais da BH-JM, uma vez que no período de 2001 a 2013, 
alguns córregos da bacia, como o Caxambu, apresentaram um aumento percentual de sua área florestal ( $\mathrm{ibid}$.).

A Lei Municipal n. 2.405/1980 (JUNDIAÍ, 1980), também intitulada Lei de Proteção aos Mananciais, proibiu na BH-JM a implantação de sistemas de tratamento de resíduos sólidos, bem como estabeleceu que todo o resíduo sólido gerado na bacia deve ser retirado das áreas protegidas. Além disso, estabeleceu que as edificações não ligadas à rede pública de esgotamento sanitário deveriam contar com fossas sépticas. Contudo, estudos realizados na BH-JM têm observado a presença de resíduos domiciliares difusos nas suas áreas de proteção e margens de suas estradas, tal como retratado por Fengler et al. (2015a), Medeiros et al. (2016) e Silva e Medeiros (2017). Esse cenário emerge a necessidade de abordagens específicas junto a população residente e transeunte da BH-JM quanto ao descarte de resíduos sólidos, como por meio de programas e iniciativas relacionadas a educação ambiental. Ademais, apesar da presença de fossas sépticas na área rural da BH-JM, evidências de lançamento de esgoto nos córregos dessa bacia, mesmo nas partes mais urbanizadas, foram relatados por Beghelli et al. (2015) e De-Carli et al. (2018).

A Lei de Proteção aos Mananciais (JUNDIAÍ, 1980) definiu, ainda, a competência dos órgãos vinculados a Prefeitura Municipal de Jundiaí na análise dos aspectos relacionados às edificações e empreendimentos econômicos na BH-JM; já no que tange a análise da proteção hídrica da bacia, esta ficou sob a competência direta do Departamento de Água e Esgoto de Jundiaí (DAE Jundiaí). Desse modo, todos os processos de licenciamento ambiental de atividades econômicas nas áreas de proteção expressas por esta Lei devem, primeiramente, passar pelos órgãos da Prefeitura e da DAE antes de serem avaliados por outros órgãos públicos.

Nesse sentido, e em observância a subordinação aos órgãos estaduais e federais, coube a Prefeitura Municipal de Jundiaí (PMJ) e a DAE fiscalizar e aplicar sanções relativas às áreas protegidas nos seguintes aspectos (JUNDIAÍ, 1980, art. 5.1):

I - condições de passagem de canalização;

II - condições de coleta, transporte e destino final de esgotos e resíduos;

III - condições e limites quantitativos de produtos nocivos que poderão ser armazenados, sem riscos para a qualidade dos recursos hídricos;

IV - emprego de defensivos e fertilizantes e prática de atividades agrícolas e de criação de animais, que deverão ser limitadas às formas que não contribuam para a deterioração dos recursos hídricos;

V - exigências a serem cumpridas pelas indústrias existentes ou em construção e o 
plano de remanejamento das que não puderem permanecer;

VI - ampliação e aumento de escala de produção dos estabelecimentos industriais;

VII - movimentação de terra;

VIII - desmatamento;

IX - uso das coleções de água;

$\mathrm{X}$ - pavimentação e impermeabilização do solo;

XI - uso do solo;

XII - demais atividades que possam vir a interferir na qualidade das coleções de água.

Diante dos requisitos legais elencados, verifica-se que há um aparato jurídico básico (e amplo) relativo à proteção ambiental e, especificamente, dos recursos hídricos de Jundiaí. Nota-se, ainda, o compromisso firmado pelo município no cumprimento dos requisitos legais ambientais, assim como a competência dada a PMJ e a DAE, a nível municipal, na tutela ambiental nas questões relativas à fiscalização e aplicação de sanções aos agentes que causem degradação ambiental. Todavia, embora se tenha criado este novo crivo jurisdicional ainda nos anos 1980, os diagnósticos ambientais apresentados demonstram uma falta de engajamento da população residente e transeunte da bacia, consubstanciada pelo lixo difuso em áreas de proteção, expansão urbana, supressão de mata ciliar e lançamento de efluentes domésticos nos tributários da BH-JM.

\subsection{Legislações relativas à Área de Proteção Ambiental de Jundiaí (APA Jundiaí) e medidas protecionistas concernentes à BH-JM}

A criação e gestão de uma APA denotam ações específicas dos órgãos gestores estaduais e municipais, uma vez que se trata de uma unidade de uso sustentável que já apresenta certo nível de ocupação antrópica, constituídas de propriedades públicas e privadas (BRASIL, 2000). Fundamentalmente, visando à sustentabilidade do uso dos recursos naturais, os órgãos gestores competentes devem estabelecer normas que limitam ou proíbam nas APAs (BRASIL, 1981, art. $9^{\circ}$ ):

A implantação e o funcionamento de indústrias potencialmente poluidoras, capazes de afetar mananciais de água;

A realização de obras de terraplenagem e a abertura de canais, quando essas iniciativas importarem em sensível alteração das condições ecológicas locais;

O exercício de atividades capazes de provocar uma acelerada erosão das terras e/ou um acentuado assoreamento das coleções hídricas;

O exercício de atividades que ameacem extinguir na área protegida as espécies raras da biota regional. 
Dentro dessas premissas, foi criado a APA Jundiaí, por meio da Lei Estadual n. 4.095/1984 (SÃO PAULO, 1984), da qual enfatizou, explicitamente, como área de proteção ambiental toda a área de drenagem da BH-JM. Contudo, inicialmente esta Lei descrevia somente como APA a porção de terra localizada nos limites municipais de Jundiaí, redação da qual foi alterada somente 22 anos depois por meio da Lei 12.290/2006 (SÃO PAULO, 2006) - momento do qual foram incluídas também as porções de terras da BH-JM localizadas em Jarinu e Campo Limpo Paulista. Assim, de forma integrada e articulada entre esses municípios, uma governança intermunicipal pode ser articulada a fim de evitar e/ou impedir atividades degradadoras do meio ambiente na bacia.

Nessa égide, destacam-se os levantamentos realizados por Fengler et al. (2015b), Medeiros et al. (2016), Silva e Medeiros (2017) e De-Carli et al. (2018), que identificaram práticas inadequadas de manejo agrícola nas cabeceiras da BH-JM, notadamente na porção territorial de Jarinu. Tais atividades, sem o correto manejo do solo, potencializam os processos erosivos e o consequente transporte de sedimentos para os tributários dessa bacia. Contudo, tais impactos tornam-se mais significativos à Jundiaí, pois são áreas estratégicas de produção de água natural para o município. Desse modo, suscita-se a necessidade de uma governança intermunicipal mais efetiva e articulada, cujos requisitos legais para a bacia sejam elaborados visando atender as particularidades e necessidades de ambos os municípios.

Posteriormente à Lei Estadual n. 4.095/1984 (SÃO PAULO, 1984), foi promulgado o Decreto Estadual n. 24.839/1986 (SÃO PAULO, 1986), o qual enquadrou o rio Jundiaí-Mirim e todos os seus afluentes em cursos d'água Classe $1^{4}$. Dessa forma, constitui-se um importante instrumento de gestão para o monitoramento da qualidade da água da BH-JM baseado no princípio do limite, uma vez que foram estabelecidos padrões de enquadramento do corpo hídrico. Especificamente, denota-se, ainda, um avanço legislativo no que diz respeito à preservação das águas da BH-JM, já que esse tipo de classificação, em nível nacional, foi estabelecido somente anos depois, a partir da Resolução CONAMA 357/05 (BRASIL, 2005).

Todavia, conforme observações de Beghelli et al. (2015), De-Carli et al. (2018) e Machado et al. (2018) a qualidade da água avaliada nos afluentes e na calha principal da BH-JM não tem correspondido à Classe 1 em

4 Segundo o Decreto Estadual n. 8.468/1976 (SÃO PAULO, 1976, art. 7, inc. 1), as águas Classe 1 são aquelas "destinadas ao abastecimento doméstico, sem tratamento prévio ou com simples desinfecção". Este Decreto estabeleceu ainda as Classes 2, 3 e 4, sendo a Classe 4 representativa das águas com usos menos exigentes e/ou que necessitam de um tratamento avançado para consumo o humano. 
função das atividades agrícolas e lançamento de efluentes domésticos. Isso demonstra as limitações enfrentadas pelos órgãos gestores que, apesar da materialização legal das políticas públicas, denota, ainda, uma dificuldade na manutenção de uma agenda ambiental para uma bacia hidrográfica. Do mesmo modo, a extensão territorial e as fontes difusas de poluição em uma área superior a 10.000 ha, como a da BH-JM, impõe, ainda, uma limitação quanto a fiscalização e implementação dessas políticas.

O Decreto Estadual n. 43.284/1998 (SÃO PAULO, 1998) visou regulamentar a Lei Estadual n. 4.095/1984 (SÃO PAULO, 1984). Nesta regulamentação foram reforçados os propósitos iniciais da criação da APA Jundiaí, principalmente no que tange a proteção dos recursos hídricos, sendo então instituída a zona de conservação hídrica, da qual abrangeu toda a extensão da BH-JM. Ao mesmo tempo foram, ainda, estabelecidas ações a fim de se evitar processos erosivos, seja por meio de planos específicos de manejo do solo agrícola ou na exigência de licenciamento ambiental em projetos urbanísticos na BH-JM.

Nos anos 1990, diante dos problemas relacionados à poluição causada por indústrias situadas nas proximidades do rio Jundiaí-Mirim, a Lei Municipal n. 3.522/1990 (JUNDIAÍ, 1990), foi promulgada a fim de vetar qualquer lançamento de substâncias poluidoras nos cursos d'água oriundas das atividades econômicas. Logo, verifica-se que, à época, a BH-JM já apresentava problemas relacionados à expansão industrial do município. Destaca-se, ainda, a importância dada à matéria, haja vista que o Projeto de Lei 4.949/1989 (JUNDIAÍ, 1989) foi recomendado pelas Comissões competentes da Casa Legislativa e aprovado por unanimidade pela Câmara de Vereadores de Jundiaí (ibid.), refletindo, assim, uma preocupação em proteger a bacia.

Em 2004 foi criado o Sistema de Proteção das Áreas da Serra do Japi, por meio da Lei Municipal Complementar 417/2004 (JUNDIAÍ, 2004), que restringiu qualquer nova ocupação na Reserva Biológica da Serra do Japi, bem como foram estabelecidos padrões rígidos de ocupação nas áreas de amortecimento da Reserva. Fanelli e Santos Junior (2013) discorrem que com a restrição de ocupação na região da Serra do Japi, que ocupa cerca de um terço do território de Jundiaí, houve uma grande ocupação nas demais áreas do município - culminando, inclusive, nos processos de conurbação entre os municípios adjacentes de Várzea Paulista e Campo Limpo Paulista.

Ademais, a Lei Municipal 417/2004 (ibid.) demonstrou ser um instrumento efetivo de proteção ambiental de um patrimônio natural. 
Consoante, Fengler et al. (2012) destacaram que a importância relativa da área de mata na zona de amortecimento da Serra do Japi variou de 46,60\% em 1989, para 69,71\% em 2010. Do mesmo modo, os autores evidenciaram que neste ínterim houve o aumento de áreas com regeneração natural em contraponto as áreas com atividades agrossilvopastoris e de reflorestamento. Assim, tais dados evidenciam que essa região foi favorecida pelas mudanças na cobertura do solo, no período avaliado, apesar da forte pressão antrópica ocasionada pela expansão urbana em seu entorno.

Nesse sentido, essa problemática pode ser melhor compreendida quando se analisa o macrozoneamento vigente em Jundiaí, onde pode ser observado a abrangência e dispersão da Zona de Estruturação e Qualificação Urbana do município e seus respectivos fragmentos na Zona de Proteção Ambiental, Hídrica e Desenvolvimento Rural. Por outro lado, nota-se uma menor ocorrência desta zona de estruturação nos limites de proteção da Serra do Japi, dado a maior restrição existente por se tratar de uma Unidade de Proteção Integral (BRASIL, 2000). Logo, observa-se um problema decorrente da criação de áreas protegidas em regiões de intenso crescimento e adensamento populacional; este fato evidencia, ainda, a necessidade de ações concretas da gestão municipal na criação e efetivação de políticas públicas de controle e direcionamento do tecido urbano, principalmente em áreas de produção hídrica enquadradas no escopo das Unidades de Uso Sustentável.

\subsection{Lei municipal de autorização de comercialização de água do rio Jundiaí-Mirim}

A Lei n. 5.032/1997 (JUNDIAÍ, 1997) autorizou a DAE a fornecer água bruta a empresas que utilizam os recursos hídricos como insumo em seus processos produtivos, mediante cobrança. Esse fornecimento ficou condicionado à autorização ad referendum da Câmara Municipal, para novas empresas ou para aquelas que almejem aumentar o fornecimento já concedido (ibid.). Diante disso, verifica-se a importância dos recursos hídricos da BH-JM à economia do município. Contudo, baseando-se nos princípios da gestão democrática e do acesso equitativo aos recursos naturais, esta autorização deveria envolver também outros atores sociais interessados nesse processo decisório, tais como organizações não governamentais e instituições de ensino e pesquisa. 
Nessa conjuntura, Coates et al. (2012) ressaltam de forma reflexiva a reciprocidade envolvida no crescimento econômico ancorado no aumento do uso industrial da água, onde: enquanto as forças econômicas ocasionam pressão nos recursos hídricos, a disponibilidade e o estado deste recurso também influenciam e/ou limitam as atividades econômicas. Do mesmo modo, deve ser considerado o viés político-econômico envolvido no processo de fornecimento deste recurso. Tal fato decorre uma vez que eventuais liberações de consumo das águas da BH-JM, por intermédio dos entes ora aludidos, possam vir a ser avaliados sem considerar critérios estritamente técnico-ambientais, assim como, com base nos usos preponderantes deste recurso, sobretudo em situações de déficit hídrico ${ }^{5}$, comum na região.

\subsection{Lei municipal de alienação de área pública}

A Lei Municipal n. 5.221/1998 (JUNDIAÍ, 1998b) reclassificou e autorizou a DAE a alienar áreas públicas localizadas no entorno da represa de acumulação de Jundiaí, na região do bairro Jardim Florestal. Entre outros fatores, o propósito foi permitir a companhia à implantação de espaços e estabelecimentos sujeitos ao cumprimento de normas e critérios específicos, tais como aqueles voltados à preservação cultural e ambiental (e.g., monumentos históricos, proteção hídrica e áreas de valor paisagístico).

A referida Lei estabeleceu alguns requisitos a serem cumpridos pelo alienador, dos quais se destacam (JUNDIAÍ, 1998b):

- Implantação de faixas de preservação permanente;

- Implantação de bosques;

- Realocação de interceptores de esgotos; e

- Uso mínimo de áreas impermeabilizadas.

Todavia, por ser tratar de um projeto urbanístico localizado em uma área de relevante interesse ambiental (JUNDIAÍ, 1980; 2015a; 2016c), houve a propositura de o alienador apresentar a elaboração do Estudo de Impacto Ambiental (EIA) e respectivo Relatório de Impacto Ambiental (RIMA) -

\footnotetext{
5 Nessa perspectiva, ressalta-se a apuração feita pelo Ministério Público de São Paulo (MPSP) a fim de verificar o volume de água bruta fornecido pela DAE a uma indústria de refrigerantes do município, sendo verificado que a companhia fornecia o volume mínimo anual de $2,5 \mathrm{mil} \mathrm{m}^{3}$ anuais ou cerca de $80 \mathrm{~L} \mathrm{~s}^{-1}$ (MPSP, 2014). Esta vazão corresponde a $20 \%$ da vazão média do rio Jundiaí-Mirim informado pelo DAE (i.e., $400 \mathrm{~L} \mathrm{~s}^{-1}$ ) (DAE, 2016).
} 
conforme preconizado na Resolução CONAMA n. 01/86 (BRASIL, 1986) assim como em atenção a Lei Orgânica Municipal (JUNDIAÍ, 2015b) ${ }^{7}$. No entanto, a Casa Legislativa rejeitou essa propositura, conforme pode ser verificado na Emenda n. 1 do Projeto de Lei 7.441/98 (JUNDIAÍ, 1998a); o que reflete, assim, uma eventual flexibilização no processo de implantação do projeto.

Assim, embora os estudos ambientais apresentados atestassem a viabilidade ambiental das intervenções propostas, bem como aludido os benefícios sociais da implantação de equipamento recreativos na área (JUNDIAÍ, 1998a), deve ser ressaltado o baixo benefício ecossistêmico propiciado pela área em termos da efetiva proteção dos recursos hídricos e da fauna e flora. Na Figura 2 (A, B, C e D) são apresentadas imagens da área em tela, onde é possível verificar a baixa representatividade de exemplares da mata nativa local, bem como a ausência de recomposição ciliar arbustiva, medidas das quais reduziriam os impactos de borda do reservatório de água do município.
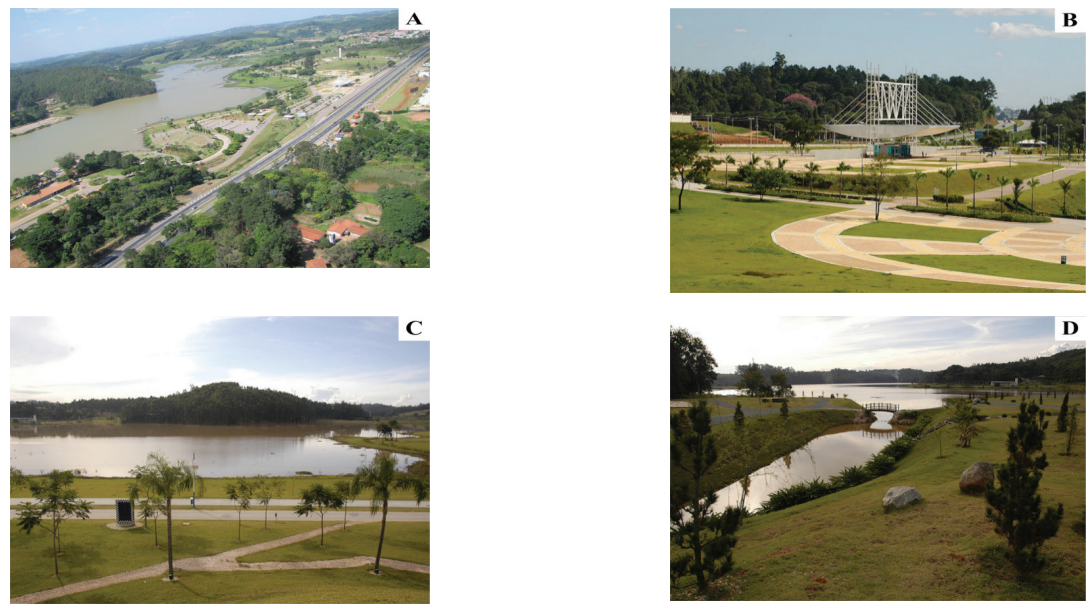

Figura 2 Imagens do Parque da Cidade $\left(500 \mathrm{mil} \mathrm{m}^{2}\right)$ localizado na margem esquerda (sentido Jundiaí-Itatiba) do km 66 da rodovia João Cereser, em Jundiaí (SP).

Fonte: Acervo fotográfico público da Prefeitura Municipal de Jundiaí (PMJ, 2005-2009).

6 A Resolução CONAMA n. 01/1986 estabeleceu a exigência da elaboração de EIA/RIMA em diversas situações e, para o caso em questão: "projetos urbanísticos, acima de 100 ha ou em áreas consideradas de relevante interesse ambiental a critério da Secretaria Especial do Meio Ambiente (SEMA) e dos órgãos estaduais ou municipais" (BRASIL, 1986, art. 2º, inc. XV).

7 A Lei Orgânica de Jundiaí estabelece que "nos serviços públicos prestados pelo Município e na sua concessão, permissão e renovação deverão ser avaliados os serviços e seu impacto ambiental (JUNDIAÍ, 2015b, art. 166)“. 
Assim, a partir das análises das imagens supracitadas, verifica-se que houve a criação de uma área cujo paisagismo foi elaborado nos moldes dos jardins europeus, em oposição à criação de uma área cujos moldes deveriam refletir, por razões ecossistêmicas, o bioma local. Não obstante, deve ser considerado que a criação de um parque nesta área veio a contribuir com a redução de especulações imobiliárias, assim como para evitar ocupações irregulares - tal como as ocorridas às margens dos reservatórios de abastecimento da capital paulista (FONTANA et al., 2014).

\subsection{Lei municipal para investimentos na barragem do rio Jundiaí-Mirim}

A Lei Municipal n. 8.203/2014 (JUNDIAÍ, 2014a) incluiu investimentos financeiros para obras de complementação da barragem do rio Jundiaí-Mirim no Plano Plurianual Municipal 2014-2017. A justificativa, expressa nesta Lei, foi à preservação de área ambiental e proteção de mananciais. No entanto, os investimentos de 4 milhões previstos (JUNDIAÍ, 2014a) foram direcionados a obras de alteamento da represa de acumulação e desapropriações de imóveis localizados nas imediações (JUNDIAÍ, 2014b). Dados do Ministério do Planejamento apontam, ainda, que entre 2007 e 2010, por meio Programa de Aceleração do Crescimento (PAC), houve um aporte de quase R $\$ 18,7$ milhões (em estágio concluído) de recursos voltados à complementação da represa de Jundiaí (BRASIL, 2017).

Assim, verifica-se que há uma notória preocupação do município e respectivos órgãos gestores na ampliação da capacidade de armazenamento de água no município sem, no entanto, explicitar a execução de ações destinadas à produção natural de água na BH-JM. Nesse sentido, considera-se, ainda, que, embora haja um aumento da área útil de armazenamento de água, esta pode ser reduzida ao longo do tempo se ações diretas na bacia também não forem executadas. Nessa perspectiva, devem ser ressaltados os problemas relacionados aos processos erosivos existentes na BH-JM (MORAES, 2003; FREITAS et al., 2013; MEDEIROS et al., 2016; MORAES, 2016; SILVA; MEDEIROS, 2017; DE-CARLI et al., 2018; MACHADO et al., 2018), dos quais intensificam o carreamento de sedimentos para o reservatório de acumulação e captação de Jundiaí.

Tais processos erosivos incorrem, ainda, em custos diretos e onerosos na manutenção da capacidade de armazenamento de água em reservatórios 
(LIU; WALLING; HE, 2017). Nesse sentido, em 2008 a DAE investiu cerca de R $\$ 1,5$ milhão em obras de desassoreamento no reservatório de acumulação, onde foi retirado mais de $100 \mathrm{mil} \mathrm{m}^{3}$ de detritos acumulados (DAE, 2008). Já em 2017 a companhia destinou cerca de R \$ 4,5 milhões para obras de desassoreamento do reservatório (DAE, 2017c). Ainda no aspecto econômico, outro fator a ser observado é o aporte excessivo de nutrientes, responsável pela proliferação descontrolada de macrófitas aquáticas em reservatórios de abastecimento (BEGHELLI et al., 2015). Esta situação já foi registrada nos reservatórios de Jundiaí, onde estudos apontaram a necessidade da retirada de $80 \%$ das macrófitas presente no reservatório de acumulação (DAE, 2017c), a um custo próximo a $\mathrm{R}$ \$ 1,1 milhão (DAE, 2017d).

Similarmente, destacam-se, ainda, os investimentos que foram previstos pela DAE para o período de 2017-2018. Neste intervalo foi relacionado uma série de investimentos em obras e serviços para o sistema de abastecimento de Jundiaí, cuja montante chega a 25 milhões (ARES-PCJ, 2017). Contudo, verifica-se que, dos 67 itens de investimentos elencados, não há nenhum diretamente relacionado a ações voltadas à redução de processos erosivos, assim como à preservação e/ou conservação de áreas estratégicas de produção natural de água na BH-JM ou para ações voltadas ao uso eficiente da água.

\subsection{Programas de incentivo de recuperação de áreas de mananciais}

Em 2014, por meio do Decreto Estadual n. 60.521/2014, o governo do estado de São Paulo instituiu o "Programa de Incentivos à Recuperação de Matas Ciliares e à Recomposição de Vegetação nas Bacias Formadoras de Mananciais de Água - Programa Mata Ciliar, com o objetivo de ampliar a proteção e conservação dos recursos hídricos e da biodiversidade [...]" (SÃO PAULO, 2014a, art. $1^{\circ}$ ). Posteriormente, este Decreto foi regulamentado pela Resolução conjunta da Secretaria de Meio Ambiente do Estado de São Paulo (SMA) n. 001/14 (SÃO PAULO, 2014b), ocasião em que foram estabelecidas as áreas iniciais prioritárias de intervenção do Programa.

Dentre outras bacias, o Programa Mata Ciliar selecionou a bacia do rio Jundiaí e a BH-JM como áreas iniciais de intervenção, com foco em ações de recuperação ambiental nas margens dos cursos d'água e nascentes na região de cabeceiras (SÃO PAULO, 2014b). Contudo, a área inicial 
de intervenção prevista no Programa para as referidas áreas foi de apenas 700 hectares (ha); o que representa 3,9\% do total de áreas beneficiadas no Estado pelo Programa (i.e., 18.077 ha) (SÃO PAULO, 2014b) e, apenas, $0,6 \%$ da área total da bacia do rio Jundiaí (i.e., 111.403 ha) (CBH-PCJ, 2016).

No âmbito municipal, a primeira tratativa legal visando à criação de um programa ambiental voltado a proteção de nascentes foi feita no início de 2016, por meio do Projeto de Lei 12.008/2016 (JUNDIAÍ, 2016d). Tal propositura foi fundamentada na importância da proteção das nascentes e cursos d'água do município, bem como em função da constatação do decréscimo da produção de água na BH-JM, dado a degradação de áreas importantes para a produção de água (ibid.). Logo, verifica-se que houve um entendimento da gestão municipal dos problemas ambientais existentes na BH-JM, bem como a necessidade da criação de medidas legais mais eficazes a fim de saná-los ou dirimi-los.

Como resultado da discussão dessa matéria, foi promulgada a Lei Municipal n. 8.607/2016 (JUNDIAÍ, 2016a), momento em que foi instituído o "Programa Nascentes de Jundiaí", cujo propósito principal foi o de estabelecer ações para recuperação, conservação e proteção dos mananciais do município. Dessa forma, criou-se, em nível municipal, um importante instrumento de proteção dos recursos hídricos, assim como foram instituídas concepções importantes, das quais se destacam (JUNDIAÍ, 2016a):

- A seleção das áreas prioritárias para proteção com base em critérios técnicos e legais;

- A inclusão do conceito de serviços ambientais e ecossistêmicos como forma de se atingir a sustentabilidade dos recursos hídricos;

- O cadastramento e apoio financeiro e/ou técnico in loco aos participantes do Programa a fim do cumprimento das metas previamente estabelecidas, com possibilidade de parcerias com entidades governamentais, setor privado e da sociedade civil.

A partir da promulgação da referida Lei (JUNDIAÍ, 2016a), iniciativas já podem ser observadas na BH-JM, na região da sub-bacia córrego da Roseira. Tais iniciativas estão sendo desenvolvidas a partir de parcerias da gestão municipal e da DAE com a organização internacional The Nature Conservancy (TNC), duas companhias de bebidas do município e uma construtora - esta última, em função de um Termo de Compromisso de Recuperação Ambiental (TCRA n. 72881/16) firmado como contrapartida à 
implantação de um loteamento de alto padrão no município (PREFEITURA REFORMA..., 2017; SÁ, 2016; SÃO PAULO, 2017).

Assim, verifica-se que a Lei Municipal n. 8.607/2016 (JUNDIAÍ, 2016a) trouxe benefícios à BH-JM, bem como propiciou a captação de recursos financeiros do setor empresarial. Apesar disso, destaca-se que essas mesmas empresas são/serão usufrutuárias dos serviços ecossistêmicos advindos da proteção das nascentes, principalmente no que tange à provisão de água. Deve ser considerado, ainda, que o crescimento industrial e urbanístico da cidade ocasiona uma pressão direta nos recursos hídricos, necessitando assim de contrapartidas diretas deste setor - principalmente dos que utilizam as águas da BH-JM em seus processos.

\subsection{Lei municipal de criação do dia do rio Jundiaí-Mirim}

A recente Lei Municipal n. 8.673/2016 (JUNDIAÍ, 2016b) instituiu o dia três de junho como o dia do rio Jundiaí-Mirim. Dessa maneira, foi criado um importante instrumento de educação ambiental voltada à BH-JM, inserido diretamente na agenda ambiental municipal. Dentre outros desdobramentos, tal promulgação decorreu em função de Jundiaí ser signatário do Programa Município VerdeAzul (PMVA) do Governo Estadual que, dentre outros requisitos, estabeleceu diretivas pedagógicas a serem seguidas em ações de educação ambiental (SÃO PAULO, 2016). Esta premissa pode ser observada explicitamente no art. 2 da Lei Municipal n. 7.381/2009 (JUNDIAÍ, 2009), que institui o calendário de datas comemorativas ambientais de Jundiaí, onde foi estabelecido que:

[...] os temas ambientais serão abordados através da inclusão no âmbito curricular, nas atividades desenvolvidas nas escolas da rede pública municipal, permeando os conteúdos, objetivos e orientações didáticas em todas as disciplinas, extensivo à sociedade, favorecendo o desenvolvimento de hábitos e atitudes sadias de conservação ambiental e respeito à natureza, na elaboração de projetos e atividades educativas, campanhas, mutirões e outras formas de divulgação e comunicação adequadas (JUNDIAÍ, 2009, art. 2).

Contudo, cabe destacar que a inclusão do rio Jundiaí-Mirim, como data comemorativa ambiental, foi inserida somente em 2016 (JUNDIAÍ, 2016b). Por outro lado, já existiam outras nove datas comemorativas ambientais instituídas no município desde 2009 (JUNDIAÍ, 2009). Destarte, verifica-se que a propositura de inclusão do rio Jundiaí-Mirim, no calendário ambiental municipal, se deu em um contexto imediatista 
a crise hídrica vivida nas bacias dos rios Piracicaba, Capivari e Jundiaí (bacias PCJ) à época (CBH-PCJ, 2015). Nesse sentido, com base na análise do Projeto de Lei 11.819/2015 (JUNDIAÍ, 2015c), que derivou a Lei Municipal n. 8.673/2016 (JUNDIAÍ, 2016b), pode ser observado que a mesma foi fundamentada na importância da conscientização da população jundiaiense acerca da preservação dos recursos naturais e, especificamente, dos recursos hídricos da BH-JM - a qual foi tratada como o maior patrimônio do município.

\subsection{Plano Diretor de ordenamento territorial}

\subsubsection{Plano Diretor de Jundiaí}

O Plano Diretor consiste em um instrumento básico e obrigatório de ordenação territorial para cidades acima de 20 mil habitantes (BRASIL, 1988) e que, salvo disposições contrárias, devem ser revistos a cada 10 anos (BRASIL, 2001). Em Jundiaí, verificou-se que matérias legislativas de ordenação territorial remota a meados dos anos 1950. Nesse contexto, destaca-se a Lei Municipal n. 503/1956 (JUNDIAÍ, 1956), da qual institui, à época, uma comissão deliberativa para o Plano Diretor do município. Desde então houve diversas atualizações, sendo o Plano Diretor de Jundiaí (PDJ) mais recente promulgado por meio da Lei n. 8.683/2016 (JUNDIAÍ, 2016c).

O PDJ foi elaborado de forma a compatibilizar suas diretrizes com o Plano de Desenvolvimento Urbano Integrado da Aglomeração Urbana de Jundiaí (AUJ) (Jundiaí, 2016c). Logo, no espectro político, tal fato veio a contribuir diretamente para a gestão da BH-JM, uma vez que seus limites abrangem mais dois municípios pertencentes à AUJ, onde um ordenamento integrado se revela essencial. O PDJ destaca-se, ainda, na matéria relacionada a proteção hídrica, uma vez que apresenta em seu planejamento mapeamentos detalhados da rede hidrográfica, nascentes e remanescentes florestais, bem como foi estabelecido o delineamento de áreas de recarga hídrica do município (ibid.). Este fato reflete uma diretriz importante e inovadora na definição de áreas prioritárias para intervenção, as quais contribuem diretamente na manutenção e/ou aumento da produção natural de água local.

Em relação ao zoneamento, o PDJ instituiu 3 grandes macrozonas no município, das quais se destaca a Macrozona de Proteção Ambiental, Hídrica e de Desenvolvimento Rural. Esta contemplou, ainda, como 
subzona, a Zona de Proteção e Recuperação Ambiental das Bacias dos Rios Jundiaí-Mirim e Capivari e Ribeirão Cachoeira/Caxambu, cujas proposituras se pautaram na (JUNDIAÍ, 2016c, art. 37):

- Fiscalização e controle para contenção da ocupação urbana irregular;

- Promoção do desenvolvimento rural com sustentabilidade ambiental, econômica e social, e estímulo à agroecologia e à agricultura familiar;

- Conservação, preservação e recuperação dos fragmentos de vegetação nativa e das áreas de preservação permanente, viabilizando a configuração de corredores ecológicos;

- Garantia da ocupação de baixa densidade, com atividades econômicas compatíveis com a produção de água.

Nas zonas especiais de proteção ambiental foi definido como taxa mínima de permeabilidade o percentual de $80 \%$ para áreas acima de dois hectares, assim como foi restringido áreas edificadas acima de 7 metros de altura (Jundiaí, 2016c). Assim, observa-se a criação de medidas a fim de se evitar a verticalização e o aumento de áreas impermeáveis, consequências diretas do adensamento populacional. Contudo, deve ser destacado que, embora seja estabelecido critérios restritivos de uso e ocupação das terras na região da BH-JM, nota-se que há uma evidente pressão antrópica na bacia já consolidada por ocupações periurbanas. Por conseguinte, deve ser apontado que no ordenamento jurídico uma norma não pode retroagir, conforme preconizado no princípio da irretroatividade. Desse modo, programas de incentivo ao aumento de áreas permeáveis para imóveis já consolidados na bacia devem ser considerados a fim de dirimir os impactos já existentes e anteriores à Lei.

Ainda na abrangência da BH-JM, destaca-se que o PDJ contemplou como Zona Especial de Proteção Ambiental as adjacências dos reservatórios de captação e acumulação, área da qual deveria se estender ao menos, por questões protecionistas/ecossistêmicas, ao longo de toda a calha principal do rio Jundiaí-Mirim. No entanto, deve ser considerado que tais áreas já se revelam com certo grau de ocupação, cuja implantação de zonas como esta demandaria vultosos recursos financeiros para desapropriações e implantação de medidas de restauração ambiental. Não obstante, medidas como esta devem ser consideradas a longo prazo visando à proteção dos recursos hídricos da bacia. 
O estabelecimento de requisitos legais comuns de ordenamento territorial entre os municípios que abrangem a bacia revela-se de fundamental importância, nomeadamente entre Jundiaí e Jarinu (neste último está localizado parte das cabeceiras da BH-JM). Contudo, Jarinu intenta a implantação de um empreendimento urbanístico, do qual já tramitou favoravelmente no processo de licenciamento ambiental (CETESB, 2017). O referido projeto, de médio-alto padrão, prevê a implantação de lotes residenciais e comerciais em uma área de 387 hectares, e abrigará cerca de 10.000 habitantes em um horizonte de 40 anos (DFREIRE, 2015).

De acordo com o zoneamento instituído pelo Plano Diretor de Jarinu, o qual atesta a compatibilidade do empreendimento (DFREIRE, 2015), a área de implantação do projeto está situada na Macrozona de Qualificação Urbana do município, da qual se caracteriza por ser uma zona:

[...] composta por áreas dotadas de infraestruturas, serviços e equipamentos públicos e comunitários, apresentando maior densidade construtiva e populacional que requerem uma qualificação urbanística e em condições de atrair investimentos imobiliários privados (Jarinu, 2009, art. 41, grifo nosso).

Diante desse zoneamento instituído pelo Plano Diretor de Jarinu (JARINU, 2009) e a luz do atual PDJ (JUNDIAÍ, 2016c), verifica-se que esse loteamento pode vir a comprometer diretamente a produção de água da BH-JM, bem como propiciar a atração de novos empreendimentos em suas adjacências. Do mesmo modo, verifica-se que os Planos Diretores de ambos os municípios têm propostas divergentes, uma vez que o PDJ visa conter a expansão urbana e o desenvolvimento rural nessa região; já o Plano Diretor de Jarinu visa atrair investimentos imobiliários privados embora determine também áreas de especial interesse ambiental nas suas proximidades.

Tais fatos evidenciam, ainda, os interesses difusos de cada município na elaboração de seus respectivos ordenamentos territoriais, uma vez que para Jundiaí, que já teve um desenvolvimento demográfico e econômico acentuado na região, direciona agora esforços protecionistas visando à segurança hídrica municipal; por outro lado, Jarinu intenta sua ampliação econômica por meio de atração de novos empreendimentos. Este fato reflete também a mudança da matriz econômica de Jarinu, cuja representatividade do setor rural vem declinando nos últimos anos, ao passo que o setor de serviços caminha em direção oposta (SEADE, 2014). 
Ressalta-se, ainda, que Jarinu não apresenta problemas relacionados ao abastecimento público de água, sendo que seus mananciais, localizados na bacia do ribeirão Maracanã, estão em boa condição e não apresentam fontes significativas de poluição (SABESP, 2012). Logo, em tese, evidencia-se que a questão hídrica não é um assunto prioritário para o município; já para Jundiaí, evidencia-se a necessidade de uma maior articulação intermunicipal, uma vez que é na porção norte e leste, que abrange grande parte da porção territorial de Jarinu na BH-JM, que estão localizadas as sub-bacias que apresentam as maiores contribuições de água ao longo do ano - dada as maiores taxas de fluxo lateral sub-superficial e de recarga do aquífero dessas regiões (MORAES, 2016).

\section{CONCLUSÃO}

O levantamento do aparato jurídico-ambiental permitiu constatar que Jundiaí apresenta uma legislação abrangente e avançada de proteção ambiental, englobando requisitos legais de ordenação do território que remota aos anos 1950. Do mesmo modo, o município dispõe de uma legislação específica de proteção dos recursos hídricos datada dos anos 1980, da qual já sofreu várias atualizações e ainda se encontra em vigor. Contudo, passados quase 4 décadas de sua promulgação, os diagnósticos ambientais apresentados apontam uma variação negativa na qualidade das águas da BH-JM, assim como sua superexploração. Igualmente, o uso e ocupação do solo mostra-se, muita das vezes, incompatível com que é exigido legalmente - como no caso das áreas de APPs retratado. Assim, a ineficiência do Estado, representados em nível municipal pela PMJ e pela DAE, na tutela deste bem ambiental, é notória, uma vez que a degradação da bacia tem se mostrado patente e constante ao longo do tempo.

Ademais, embora o levantamento do aparato jurídico-ambiental relacionado à BH-JM tenha identificado instrumentos legais protecionistas concretos, deve ser considerado, ainda, que uma melhor efetivação da gestão intermunicipal da bacia se revela também fundamental, uma vez que $45 \%$ da sua área está localizada fora do limite municipal de Jundiaí (áreas das quais foram inseridas somente em 2006 por força de Lei, após 22 anos da criação da APA Jundiaí, ocasionando um prejuízo nas discussões acerca dessa questão). Para esta situação, medidas legais que podem favorecer o diálogo ambiental entre os municípios foram evidenciadas, tais 
como o Conselho de Desenvolvimento da Aglomeração Urbana de Jundiaí (CDAUJ) e o Conselho Gestor da APA Jundiaí. Tais ações tornam-se fundamentais a fim de atender aos interesses difusos existentes em cada município pertencente à BH-JM.

Verificou-se também que a Reserva Biológica da Serra do Japi conta com um arcabouço jurídico mais protetivo e, em contraponto, a BH-JM tem uma legislação menos restritiva; este fato acaba ocasionado uma maior pressão antrópica nessa bacia em termos comparativos. Tal situação é, ainda, agravada em decorrência dos diversos interesses, atores sociais, impactos e complexidade de relações existentes em uma bacia, tornando a efetiva aplicação do aparato legal um desafio a ser enfrentado. Desse modo, evidencia-se a necessidade de se repensar o futuro do munícipio no que tange a segurança hídrica, bem como a necessidade de a coletividade compreender a importância da BH-JM e, assim, reivindicarem do poder público a efetiva implementação dos requisitos existentes. Ademais, deve ser entendido, ainda, o dever da coletividade na defesa desse bem, uma vez que a gestão de uma bacia não deve se pautar somente na criação e execução de leis e regras pelo Estado.

Por fim, diante dos resultados observados, recomenda-se, sumariamente, as seguintes diretrizes de gestão para a BH-JM: (i) adoção de programas de incentivos a criação de Reservas Particulares do Patrimônio Natural (RPPNs) e aquisição e/ou desapropriação de terras a fim de proteger áreas estratégicas de produção de água, assim como para conter a especulação imobiliária; (ii) estabelecimento de diretrizes de gestão integrada com os demais municípios da AUJ e com o governo estadual; (iii) maior incentivo aos pagamentos pecuniários pelos serviços ambientais e/ou ecossistêmicos aos produtores rurais da BH-JM; (iv) incentivo a participação pública dos diversos atores sociais nos processos decisórios de implantação de medidas protecionistas na BH-JM; e (v) criação de grupos de trabalho pela PMJ e articulados com a DAE a fim de verificar constantemente usos irregulares das terras.

\section{REFERÊNCIAS}

ALESP - ASSEMBLEIA LEGISLATIVA DO ESTADO DE SÃO PAULO. Pesquisa da base de legislação [banco de dados on line]. São Paulo: ALESP, [s.d.]. Disponível em: <https://www.al.sp.gov.br/alesp/pesquisalegislacao/>. Acesso em: 12 fev. 2017. 
ARES-PCJ - AGÊNCIA REGULADORA DOS SERVIÇOS DE SANEAMENTO DAS BACIAS HIDROGRÁFICAS DOS RIOS PIRACICABA, CAPIVARI E JUNDIAÍ. Reajuste das tarifas de água $e$ esgoto do municipio de Jundiai, Processo administrativo ARES-PCJ n. 213/2016. Parecer consolidado ARES-PC n. 08/2017 - DFB. Americana: ARES-PCJ, 2017.

BEGHELLI, F. G. S. et al. Uso do índice de estado trófico e análise rápida da comunidade de macroinvertebrados como indicadores da qualidade ambiental das águas na Bacia do Rio Jundiaí-Mirim - SP - BR. Brazilian Journal of Aquatic Science and Technology, v. 19, n. 1, p. 13-22, 2015.

BRASIL. Casa Civil. Lei n. 6.902, de 27 de abril de 1981. Dispõe sobre a criação de Estações Ecológicas, Áreas de Proteção Ambiental e dá outras providências. Brasília, DF: Diário Oficial da União, 1981.

BRASIL. Conselho Nacional do Meio Ambiente. Resolução n. 01 de 23 de janeiro de 1986. Estabelece as definições, as responsabilidades, os critérios básicos e as diretrizes gerais para uso e implementação da Avaliação de Impacto Ambiental como um dos instrumentos da Política Nacional do Meio Ambiente (Licenciamento Ambiental - Normas e procedimentos). Brasília, DF: Diário Oficial da União, 1986.

BRASIL. Casa Civil. Constituição da República Federativa do Brasil, Texto constitucional promulgado em 5 de outubro de 1988. Brasília, DF: Diário Oficial da União, 1988.

BRASIL. Casa Civil. Lei n. 9.985, de 18 de julho de 2000. Regulamenta o art. 225, $\S 1^{\circ}$, incisos I, II, III e VII da Constituição Federal, institui o Sistema Nacional de Unidades de Conservação da Natureza e dá outras providências. Brasília, DF: Diário Oficial da União, 2000.

BRASIL. Casa Cívil. Lei n. 10.257, de 10 de julho de 2001, Estatuto da Cidade. Regulamenta os arts.182 e 183 da Constituição Federal, estabelece diretrizes gerais da política urbana e dá outras providências. Brasília, DF: Diário Oficial da União, 2001.

BRASIL. Conselho Nacional do Meio Ambiente. Resolução n. 357, de 17 de março de 2005. Dispõe sobre a classificação dos corpos de água e 
diretrizes ambientais para o seu enquadramento, bem como estabelece as condições e padrões de lançamento de efluentes, e dá outras providências. Brasília, DF: Diário Oficial da União, 2005.

BRASIL. MinistériodoPlanejamento.Ampliação doSAA-complementação da represa do Rio Jundiai-Mirim - Jundiaí - SP, Programa de Aceleração do Crescimento (PAC). Brasília, DF: Ministério do Planejamento, 2017. Disponível em: <http://www.pac.gov.br/obra/23705>. Acesso em: 4 ago. 2017.

CBH-PCJ - COMITÊ DAS BACIAS HIDROGRÁFICAS DOS RIOS PIRACICABA, CAPIVARI E JUNDIAÍ. Relatório da situação dos recursos hídricos 2015, versão simplificada (ano base: 2014). Piracicaba: Parla, 2015. (Série UGRHI 05 - Bacias PCJ).

CBH-PCJ - COMITÊ DAS BACIAS HIDROGRÁFICAS DOS RIOS PIRACICABA, CAPIVARI E JUNDIAÍ. Relatório da situação dos recursos hídricos 2016, versão completa (ano base: 2015). Piracicaba: CBH-PCJ/Agência-PCJ, 2016.

CETESB - COMPANHIA AMBIENTAL DO ESTADO DE SÃO PAULO. Súmula do Parecer Técnico 206/17/IE, Processo 345/2014 (Loteamento Campo Verde). Departamento de Avaliação Ambiental de Empreendimentos - IE/CESTESB. São Paulo: CETESB, 2017. Disponível em: <http://arquivos.ambiente.sp.gov.br/consema/2017/06/sumula_do parecer_tecnico_cetesb-206-17-ie_sobre_o_eia-rima_do_loteamento_ campo_verde.pdf $>$. Acesso em: 2 nov. 2017.

CMJ - CÂMARA MUNICIPAL DE JUNDIAÍ. OpenLegis - Sistema Aberto de Gestão Legislativa, Jundiaí: CMJ, [s.d.]. Disponível em: $<\mathrm{http}$ //sapl.camarajundiai.sp.gov.br/generico/norma_juridica_pesquisar_ form?incluir=0>. Acesso em: 12 fev. 2017.

COATES, D. et al. Water demand: what drives consumption? In: ANDRZEJEWSKI, C. et al. (Eds.). Managing water under uncertainty and risk: The United Nations World Water Development Report 4. v. 1. Paris: Unesco, 2012. p. 44-76.

COBRAPE - COMPANHIA BRASILEIRA DE PROJETOS E EMPREENDIMENTOS. Plano municipal de saneamento básico de água e esgoto de Jundiai: relatório síntese. Jundiaí: Cobrape, 2016. 
DAE - DEPARTAMENTO DE ÁGUA E ESGOTO DE JUNDIAÍ. Escavadeira hidráulica utilizada no desassoreamento é uma das únicas no Brasil. Arquivo de Notícias, 30 set. 2008. Disponível em: <https:// www.daejundiai.com.br/2008/09/escavadeira-hidraulica-utilizada-nodesassoreamento-e-uma-das-unicas-no-brasil/>. Acesso em: 8 jun. 2017.

DAE - DEPARTAMENTO DE ÁGUA E ESGOTO DE JUNDIAÍ. Legislação. Disponível em: <https://www.daejundiai.com.br/legislacao/>. Acesso em: 12 fev. 2017a.

DAE - DEPARTAMENTO DE ÁGUA E ESGOTO DE JUNDIAÍ. Memória: o saneamento em Jundiaí. Disponível em: <www.daejundiai. com.br/memoria>. Acesso em: 11 maio 2016.

DAE-DEPARTAMENTO DE ÁGUA E ESGOTO DE JUNDIAÍ. Retirada de macrófitas e desassoreamento na represa de captação têm início. Arquivo de Notícias, 30 out. 2017b. Disponível em: $<$ https://www.daejundiai.com. br/2017/10/\%e2\%80\%8bretirada-de-macrofitas-e-desassoreamento-narepresa-de-captacao-tem-inicio/>. Acesso em: 2 nov. 2017.

DAE - DEPARTAMENTO DE ÁGUA E ESGOTO DE JUNDIAÍ. Processo 632/17: desassoreamento da represa de captação. Contrato 040/17 - Processos DAE S/A. Transparência/Licitações e Contratos/ Contratos Ativos. Jundiaí: DAE, 2017c. Disponível em: $<$ https://www. daejundiai.com.br/wp-content/uploads/2017/02/contrato-040.17.pdf $>$. Acesso em: 6 nov. 2017.

DAE - DEPARTAMENTO DE ÁGUA E ESGOTO DE JUNDIAÍ. Processo 543/17: serviço de retirada de plantas macrófitas da represa de acumulação, Contrato 034/17 - Processos DAE S/A. Transparência/ Licitações e Contratos/Contratos Ativos. Jundiaí: DAE, 2017d. Disponível em: $\quad<$ https://www.daejundiai.com.br/wp-content/uploads/2017/02/ Contrato-034.17.pdf $>$. Acesso em: 6 nov.2017.

DE-CARLI, B. P. et al. Relationship between land use and water quality in a subtropical river basin. Fronteiras: Journal of Social, Technological and Environmental Science, v. 7, n. 3, p. 245-261, 2018.

DFREIRE. Relatório de impacto ambiental (RIMA): empreendimento urbanístico Campo Verde, Jarinu - Lote 5 Desenvolvimento Urbano S. A. São Paulo: DFreire, 2015. Disponível em: <https://drive.google.com/a/ 
agenciapcj.org.br/file/d/172kjPbRUigTj7CZQVeSWas_DM0D85sYs/ view? usp=sharing $>$. Acesso em: 14 jan. 2016.

EM JUNDIAÍ, NASCENTES VAI RECUPERAR ÁREA IGUAL A 59 CAMPOS DE FUTEBOL. GOVERNO DO ESTADO DE SÃO PAULO. Portal do Governo, 20 jan. 2017. Disponível em: <http://www.saopaulo. sp.gov.br/spnoticias/ultimas-noticias/nascentes-programa-recupera-areaigual-59-campos-de-futebol-em-jundiai/>. Acesso em: 13 out. 2017.

FANELli, A. F. D. M.; SANTOS JUNIOR, W. R. D. O Aglomerado Urbano de Jundiaí (SP) e os desafios para a mobilidade metropolitana paulista. Cadernos Metrópole, v. 15, p. 461-487, 2013.

FENGLER, F. H. et al. Análise temporal da cobertura do solo na zona de amortecimento de reserva biológica Revista Brasileira de Ciências Ambientais, v. 25, p. 37-47, 2012.

FENGLER, F. H. et al. Desenvolvimento da percepção ambiental de alunos de pós-graduação em Ciências Ambientais da Unesp Sorocaba por meio da abordagem construtivista de ensino. Revista Brasileira de Pós-Graduação, v. 12 , n. 29 , p. $805-834,2015$ a.

FENGLER, F. H. et al. Qualidade ambiental dos fragmentos florestais na bacia hidrográfica do Rio Jundiaí-Mirim entre 1972 e 2013. Revista Brasileira de Engenharia Agricola e Ambiental, v. 19, p. 402-408, 2015 b.

FONTANA, L. et al. The eutrophication history of a tropical water supply reservoir in Brazil. Journal of Paleolimnology, v. 51, n. 1, p. 29-43, 2014.

FREITAS, E. P. et al. Indicadores ambientais para áreas de preservação permanente. Revista Brasileira de Engenharia Agrícola e Ambiental, v. 17, p. 443-449, 2013.

GIL, A. C. Métodos e técnicas de pesquisa social. 6. ed. São Paulo: Atlas, 2008.

IBGE - INSTITUTO BRASILEIRO DE GEOGRAFIA E ESTATÍSTICA. Estimativas da população residente nos municípios e para as unidades da federação brasileiros com data de referência em $1^{\circ}$ de julho de 2018, Diretoria de Pesquisas - DPE, Coordenação de População e Indicadores Sociais - COPIS. Brasília, DF: IBGE, 2018. 
JARINU. Câmara Municipal de Jarinu. Lei complementar n. 97, de 22 de novembro de 2006. Institui o Plano Diretor de Jarinu. Jarinu: Câmara Municipal de Jarinu, 2009.

JUNDIAÍ. Câmara Municipal de Jundiaí. Lei n. 503, de 18 de agosto de 1956, Cria a comissão deliberativa do Plano Diretor. Jundiaí: Imprensa Oficial do Município de Jundiaí, 1956.

JUNDIAÍ. Câmara Municipal de Jundiaí. Lei municipal n. 2.405, de 10 de Junho de 1980. Lei de Proteção aos Mananciais. Disciplina o uso do solo para proteção dos recursos hídricos de interesse municipal, e dá providências correlatas (atualizada até a Lei 7.503 de 2010). Jundiaí: Imprensa Oficial do Município de Jundiaí, 1980.

JUNDIAÍ. Câmara Municipal de Jundiaí. Projeto de Lei 4.949, de 21 de Junho de 1989. Veda lançar poluente no rio Jundiaí-Mirim. Jundiaí: Imprensa Oficial do Município de Jundiaí, 1989.

JUNDIAÍ. Câmara Municipal de Jundiaí. Lei n. 3.522, de 06 de abril de 1990. Veda lançar poluente no rio Jundiaí-Mirim. Jundiaí: Imprensa Oficial do Município de Jundiaí, 1990.

JUNDIAÍ. Câmara Municipal de Jundiaí. Lei n. 5.032, de 08 de setembro de 1997. Autoriza o DAE - Departamento de Águas e Esgotos a fornecer a empresas água do rio Jundiaí-Mirim. Jundiaí: Imprensa Oficial do Município de Jundiaí, 1997.

JUNDIAÍ. Câmara Municipal de Jundiaí. Projeto de Lei 7.441, de 28 de dezembro de 1998. Reclassifica e autoriza alienação, pelo DAE, de áreas públicas situadas no Jardim Florestal, para implantação de equipamento recreativo e urbanização do entorno da represa de acumulação do rio Jundiaí-Mirim. Jundiaí: Imprensa Oficial do Município de Jundiaí, 1998a.

JUNDIAÍ. Câmara Municipal de Jundiaí. Lei n. 5.221, de 31 de dezembro de 1998. Reclassifica e autoriza alienação, pelo DAE, de áreas públicas situadas no Jardim Florestal, para implantação de equipamento recreativo e urbanização do entorno da represa de acumulação do rio Jundiaí-Mirim. Jundiaí: Imprensa Oficial do Município de Jundiaí, 1998b.

JUNDIAÍ. Câmara Municipal de Jundiaí. Decreto n. 18.148, de 07 de fevereiro de 2001. Reserva faixas de preservação ao longo dos cursos 
d'água visando a manutenção da vegetação natural nela existente. Jundiaí: Imprensa Oficial do Município de Jundiaí, 2001.

JUNDIAÍ. Câmara Municipal de Jundiaí. Lei complementar 417, de 29 de dezembro de 2004. Cria o sistema de proteção das áreas da serra do Japi e revoga dispositivos do Plano Diretor (atualizada até a Lei Complementar n. 471, de 24 de março de 2009). Jundiaí: Imprensa Oficial do Município de Jundiaí, 2004.

JUNDIAÍ. Câmara Municipal de Jundiaí. Lei n. 7.381, de 14 de dezembro de 2009. Institui o calendário de datas comemorativas ambientais. Jundiaí: Imprensa Oficial do Município de Jundiaí, 2009.

JUNDIAÍ. Câmara Municipal de Jundiaí. Lei n. 8.203, de 28 de abril de 2014, Altera o Plano Plurianual 2014/2017, para prever, entre as ações da DAE S/A - Água e Esgoto, a complementação da barragem do rio Jundiaí-Mirim/Parque Ecológico. Jundiaí: Imprensa Oficial do Município de Jundiaí, 2014a.

JUNDIAÍ. Câmara Municipal de Jundiaí. Projeto de Lei 11.520, de 24 de março de 2014, Altera o Plano Plurianual 2014/2017, para prever, entre as ações da DAE S/A - Água e Esgoto, a complementação da barragem do Rio Jundiaí-Mirim/Parque Ecológico. Jundiaí: Imprensa Oficial do Município de Jundiaí, 2014b.

JUNDIAÍ. Câmara Municipal de Jundiaí. Lei municipal n. 8.517, de 26 de outubro de 2015, Altera a Lei 5.307/99, que autorizou criação da DAE S/A - Água e Esgoto, para prever isenção da tarifa de água dos imóveis onde residam pessoas com necessidades especiais ou acamadas. Jundiaí: Imprensa Oficial do Município de Jundiaí, 2015a.

JUNDIAÍ. Câmara Municipal de Jundiaí. Lei orgânica do município de Jundiai, Promulgada em 05 de abril de 1990 e atualizada até a Emenda à Lei Orgânica 67, de 22 de dezembro de 2015. Jundiaí: Imprensa Oficial do Município de Jundiaí, 2015 b.

JUNDIAÍ. Câmara Municipal de Jundiaí. Projeto de Lei 11.819, de 12 de Junho de 2015, Inclui no calendário de datas comemorativas ambientais o "Dia do rio Jundiaí-Mirim" (03 de junho). Jundiaí: Imprensa Oficial do Município de Jundiaí, 2015c. 
JUNDIAÍ. Câmara Municipal de Jundiaí. Lei n. 8.607, de 16 de março de 2016, Cria o Programa "Nascentes de Jundiaí", de conservação, recuperação e proteção de mananciais. Jundiaí: Imprensa Oficial do Município de Jundiaí, 2016a.

JUNDIAÍ. Câmara Municipal de Jundiaí. Lei n. 8.673, de 15 de junho de 2016, Inclui no calendário de datas comemorativas ambientais o "Dia do rio Jundiaí-Mirim" (03 de junho). Jundiaí: Imprensa Oficial do Município de Jundiaí, 2016b.

JUNDIAÍ. Câmara Municipal de Jundiaí. Lei n. 8.683, de 07 de julho de 2016, Institui o Plano Diretor do Município de Jundiaí, e dá outras providências. Jundiaí: Imprensa Oficial do Município de Jundiaí, 2016c.

JUNDIAÍ. Câmara Municipal de Jundiaí. Projeto de Lei 12.008, de 14 de março de 2016. Cria o Programa "Nascentes de Jundiaí", de conservação, recuperação e proteção de mananciais. Jundiaí: Imprensa Oficial do Município de Jundiaí, 2016d.

LIU, C.; WALLING, D. E.; HE, Y. Review: the international sediment Initiative case studies of sediment problems in river basins and their management. International Journal of Sediment Research, 2017.

MACHADO, F. H. et al. Environmental impacts of inter-basin water transfer on water quality in the Jundiaí-Mirim river, south-east Brazil. International Journal of Environmental Impacts, v. 1, p. 81-91, 2018.

MEDEIROS, G. A. et al. Environmental assessment using landscape analysis methodology: the case of the Jundiaí Mirim river basin, Southeast Brazil. WIT Transactions on Ecology and the Environment, v. 203, p. 2536, 2016.

MEDEIROS, G. A. et al. Water quality, pollutant loads, and multivariate analysis of the effects of sewage discharges into urban streams of Southeast Brazil. Energy, Ecology and Environment, v. 2, n. 4, p. 259-276, 2017.

MELLO, L. F.; SATHLER, D. A demografia ambiental e a emergência dos estudos sobre população e consumo. Revista Brasileira de Estudos de População, Rio de Janeiro, v. 32, n. 2, p. 357-380, 2015. 
MORAES, J. F. L. Diagnóstico agroambiental para gestão e monitoramento da bacia do rio Jundiaí-Mirim. Relatório final $2^{\text {a }}$ Fase. Processo Fapesp: 98/14181-5: Execução: Instituto Agronômico de Campinas - IAC, Instituto de Economia Agrícola - IEA, Prefeitura do Município de Jundiaí, DAE S/A. Campinas: IAC, 2003.

MORAES, J. F. L. Diagnóstico agroambiental para gestão e monitoramento da bacia do rio Jundiai-Mirim. Relatório final (Novembro de 2016). Fundação de Apoio à Pesquisa Agrícola - FUNDAG. Execução: Instituto Agronômico de Campinas - IAC. Campinas: IAC, 2016. 145 p.

MPSP-MINISTÉRIO PÚBLICODOESTADODESÃO PAULO.Portaria n. 3 de 2014, [autos públicos do processo]. Apuração do fornecimento de água bruta pelo DAE-Jundiaí à "Coca-Cola FEMSA Brasil” - Grupo Spal Indústria Brasileira de Bebidas S/A, do grupo FEMSA(Fomento Econômico Mexicano) e a influência deste fornecimento na captação realizada no Rio Atibaia, considerando a contrariedade aos Termos da Portaria de Outorga e à legislação aplicável. GAEMA/PCJ (Núcleo Campinas). Campinas: MPSP, 2014. Disponível em: <http://www.mpsp.mp.br/portal/page/portal/ comunicacao/Newsletter/imagens_newsletter/14.1097.006-2014.pdf>. Acesso em: 18 mar. 2016.

OLIVEIRA, J. A. Trabalho 'muda' bacias e mapeia 1,4 mil nascentes. Prefeitura Municipal de Jundiai - Notícias, 1 fev. 2016. Disponível em: $\quad<$ https://www.jundiai.sp.gov.br/noticias/2016/02/01/trabalho-mudabacias-e-mapeia-14-mil-nascentes-de-jundiai/> . Acesso em: 13 out. 2017.

PMJ - PREFEITURA MUNICIPAL DE JUNDIAÍ. Planejamento Urbano e Meio Ambiente. Leis ambientais: atos normativos. Jundiaí: PMJ, 2016?a. Disponível em: <https://www.jundiai.sp.gov.br/planejamento-e-meioambiente/legislacao/leis-ambientais/>. Acesso em: 12 fev. 2017.

PMJ - PREFEITURA MUNICIPAL DE JUNDIAÍ. Planejamento Urbano e Meio Ambiente. Departamento de Licenciamento de Obras e Instalações. Legislação. Jundiaí: PMJ, 2016?-b. Disponível em: <https://www.jundiai. sp.gov.br/planejamento-e-meio-ambiente/obras-particulares/legislacao/> . Acesso em: 12 fev. 2017. 
PMJ - PREFEITURA MUNICIPAL DE JUNDIAÍ. Parque da Cidade. Jundiaí: PMJ, 2005-2009. 14 fotografias. Disponível em: <https://www. flickr.com/photos/prefeituradejundiai/sets/72157627450366676/>. Acesso em: 11 dez. 2016.

PREFEITURA REFORÇA PARCERIA COM PROJETO 'NASCENTES JUNDIAÍ'. Prefeitura Municipal de Jundiai - Notícias, 10 abr. 2017. Disponível em: <https://www.jundiai.sp.gov.br/noticias/2017/04/10/ prefeitura-reforca-parceria-com-projeto-nascentes-jundiai/>. Acesso em: 13 out. 2017.

REVESZ, R. L.; STAVINS, R. N. Environmental law. In: POLINSKY, A. M.; SHAVELL, S. (Eds.). Handbook of law and economics. v. 1. North Holland: Elsevier, 2007. p. 499-589.

SÁ, R. Cidade ganha Programa 'Nascentes Jundiaí'. Prefeitura Municipal de Jundiai - Notícias, 22 mar. 2016. Disponível em: <https://www. jundiai.sp.gov.br/noticias/2016/03/22/cidade-ganha-programa-nascentesjundiai/>. Acesso em: 13 out. 2017.

SABESP - COMPANHIA DE SANEAMENTO BÁSICO DO ESTADO DE SÃO PAULO. Relatório anual de qualidade da água: município de Jarinu. São Paulo: Sabesp, 2012. Disponível em: <http://www.sabesp. com.br/calandraweb/toq/2012/Jarinu.pdf $>$. Acesso em: 14 out. 2016.

SÃO PAULO (Estado). Decreto n. 8.468, de 8 de setembro de 1976. Aprova o regulamento da Lei n. 997, de 31 de maio de 1976, que dispõe sobre a prevenção e o controle da poluição do meio ambiente. São Paulo: Diário Oficial do Estado de São Paulo, 1976.

SÃO PAULO (Estado). Lei n. 4.095, de 12 de junho de 1984. Declara área de proteção ambiental a região urbana e rural do Município de Jundiaí (atualizada até a Lei n. 12.290, de 2 de março de 2006). São Paulo: Diário Oficial do Estado de São Paulo, 1984.

SÃO PAULO (Estado). Decreto n. 24.839, de 6 de março de 1986. Dispõe sobre o reenquadramento do Rio Jundiaí-Mirim e seus afluentes na classificação prevista no Anexo do Decreto n. 10.755, de 22 de novembro de 1977. São Paulo: Assembleia Legislativa do Estado de São Paulo ALESP, 1986. 
SÃO PAULO (Estado). Decreto Estadual n. 43.284, de 3 de julho de 1998. Regulamenta as Leis n.s 4.023, de 22 de maio de 1984, e n. 4.095, de 12 de junho de 1984, que declaram áreas de proteção ambiental as regiões urbanas e rurais dos Municípios de Cabreúva e Jundiaí, respectivamente, e dá providências correlatas. São Paulo: Diário Oficial do Estado de São Paulo, 1998.

SÃO PAULO (Estado). Lei n. 12.290, de 2 de março de 2006. Altera os limites da Área de Proteção Ambiental - APA de Jundiaí, na forma que especifica. São Paulo: Diário Oficial do Estado de São Paulo, 2006.

SÃO PAULO (Estado). Decreto Estadual n. 60.521, de 5 de junho de 2014. Institui o Programa de Incentivos à Recuperação de Matas Ciliares e à Recomposição de Vegetação nas Bacias Formadoras de Mananciais de Água, institui a unidade padrão Árvore-Equivalente e dá providências correlatas. São Paulo: Diário Oficial do Estado de São Paulo, 2014a.

SÃO PAULO (Estado). Resolução conjunta SMA/SSRH n. 001, de 05 de junho de 2014, Define as áreas de intervenção do Programa de Incentivos à Recuperação de Matas Ciliares e à Recomposição de Vegetação nas Bacias Formadoras de Mananciais de Água - Programa Mata Ciliar, de que trata o Decreto n. 60.521, de 5 de junho de 2014. São Paulo: Diário Oficial do Estado de São Paulo, 2014b.

SÃO PAULO (Estado). Município VerdeAzul: orientações do PMVA ciclo 2016, São Paulo: Secretaria de Estado do Meio Ambiente, 2016. Disponível em: $\quad<$ http://arquivos.ambiente.sp.gov.br/municipioverdeazul/2011/11/ PMVA-MANUAL.pdf $>$. Acesso em: 05 de junho de 2017.

SEADE - FUNDAÇÃO SISTEMA ESTADUAL DE ANÁLISE DE DADOS. Perfil municipal. Perfil municipal de Jundiaí, Jarinu e Campo Limpo Paulista. Portal de Estatísticas do Estado de São Paulo, Informações dos Municípios Paulistas - IMP, Governo do estado de São Paulo. São Paulo: Seade, 2014. Disponível em: <http://www.imp.seade.gov.br/ frontend/\#/perfil>. Acesso em: 24 set. 2016.

SEADE - FUNDAÇÃO SISTEMA ESTADUAL DE ANÁLISE DE DADOS. Perfil municipal. Perfil municipal de Jundiaí, Jarinu e Campo Limpo Paulista. Portal de Estatísticas do Estado de São Paulo, Informações 
dos Municípios Paulistas - IMP, Governo do estado de São Paulo. São Paulo: SEADE, 2016. Disponível em: <http://www.imp.seade.gov.br/ frontend/\#/perfil $>$. Acesso em: 24 Setembro de 2016.

SILVA, C. O. F.; MEDEIROS, G. A. Avaliação ambiental e morfométrica da bacia do rio Jundiaí-Mirim: diagnósticos e subsídios para gestão ambiental. Boletim Campineiro de Geografia, Campinas, v. 7, n. 2, p. 441454, 2017.

SOUZA, C. Políticas públicas: uma revisão da literatura. Sociologias, Porto Alegre, v. 8, n. 16, p. 20-45, 2006.

SPADOTTO, A. J.; BARREIRO, M. D. P. R.; MEDEIROS, G. A. Inferencias sobre la ley brasilera de delitos ambientales en comparación con el código penal colombiano. Veredas do Direito, Belo Horizonte, v. 14, n. 28 , p. 221-249, 2017.

Artigo recebido em: 08/10/2018. Artigo aceito em: 08/07/2019.

\section{Como citar este artigo (ABNT):}

MACHADO, F. H.; FENGLER, F. H.; MEDEIROS, G. A. Políticas públicas e proteção ambiental: análise das medidas legais aplicáveis a uma bacia hidrográfica paulista. Veredas do Direito, Belo Horizonte, v. 16, n. 35, p. 369-402, maio/ago. 2019. Disponível em: $<$ http://www.domhelder. edu.br/revista/index.php/veredas/article/view/1386>. Acesso em: dia mês. ano. 